\title{
Assessment of Heat Recovery and Recovery Efficiency of a Seasonal Thermal Energy Storage System in a Moist Porous Medium
}

\author{
M. A. Dada ${ }^{*}$ and A. Benchatti \\ Laboratoire de Mécanique, University of Laghouat, B.P. 37G, Laghouat 03000, Algeria \\ Email: abder.dada@lagh-univ.dz
}

\begin{abstract}
Thermal energy storage has received a great interest by researchers and industrials as part of designing new systems able to store and deliver thermal energy efficiently for long periods, especially in regions characterized by important solar energy potential. The aim of this preliminary work is to simulate the performance of a novel seasonal heat storage system dedicated to store heat in the ground during hot period then to recover it during cold period. The system investigated herein is a ground heat exchanger buried at only $8 \mathrm{~m}$ below the underground while other technologies go deeper than $100 \mathrm{~m}$. Several case studies have been simulated according to different types of hot fluid carrier and moisture content of the porous medium. Comsol Multiphysics was used to model heat exchange between a fluid carrier flowing through a GHX, and a partially saturated porous medium composed essentially of gravel and located at about $0.5 \mathrm{~m}$ underground. Performance of the system was evaluated for a one-year period in order to get a good estimation of long-term heat storage and recovery. The results showed that the use of gasoline as a fluid carrier will yield higher temperature levels than the other fluids particularly during cold season; however, the use of water allowed for the storage and recovery of bigger heat energy than gasoline or glycol do. However, moisture content of the porous medium did not influence the whole process. System heat recovery has been enhanced by the use of two ducts to extract more heat from the underground. This approach led to a remarkable increase in temperature levels, as well as heat energy and recovery efficiency which went up from $41 \%$ when using only 1 duct to $71 \%$.
\end{abstract}

Keywords: Heat storage, Long-term, Underground, Heat recovery, Recovery efficiency.

\section{INTRODUCTION}

Underground thermal energy storage (UTES) is a sustainable technology destined to store and deliver energy at particular periods, such as winter, when heat demand is extremely high. This concept acquired a large focus because of society's energy need for heating or cooling (during summer), and to mitigate environmental issues dealing with energy production and supply. One of the UTES technology applications is seasonal storage in porous media, which can be defined as the process of storing heat in the ground during hot season which lasts several months, and then delivering it during the cold season. Seasonal storage systems can be designed particularly in hot sunny regions to collect and store solar heat energy for later use, and the most promising applications are found underground by means of borehole heat exchangers buried in soil.

A lot of work has been carried out for studying ground heat exchangers (GHX) as part of heat storage and recovery, but only few were dedicated for the assessment of recovery efficiency or heat amount recovered during cold season. Medjelled \& al (2008) conducted a set of experiments to determine thermal parameters and overall heat transfer coefficient in a sandy unsaturated porous media. The scope this study was to evaluate thermal conductivity, heat capacity and global heat transfer coefficient variation with depth of the thermal storage medium. Chiasson \& al (2010) led a simulation study of a horizontal GHX by taking into account time-varying thermal loading and weather conditions. The results provided a good insight for the design of their heat exchanger. Lanini \& al (2014) investigated a 3D numerical model to simulate different type of U-tube borehole energy storage system. Their results were validated according to experimental data and numerical results. Rabin \& al (1991) simulated a helical GHX for purpose of long-term thermal energy storage. Validation of the numerical model was carried out with experimental data and an analytical solution and the results were found to be in a good agreement. Diersch \& al (2010) simulated arrays of borehole heat exchangers (BHE) buried at $100 \mathrm{~m}$ underground using finite 
element method (FEM). Their results were benchmarked against an analytical method based on Eskilson and Claeson's model and FEM developed by Al-Khouri. Their model was in a good agreement with the aforementioned methods, and it allows for the prediction of temperature levels to be recovered during cold months. They also found that operating UTES system in a laminar regime will yield better performance than in turbulent regime. A sensitivity study performed by Welsh \& al (2015) focused on the influence of some design parameters on the performance of a medium deep UTES system by means of BHE. The results indicated that the performance heat storage and recovery tends to increase by time, and there was a great influence of design parameters on the efficiency of the system.

From what described above, it was noticed that the majority of research focused on the study of vertical GHX that go down to $100-200 \mathrm{~m}$. To do differently, we chose to assess the performance of a novel GHX configuration, which is a horizontal heat exchanger buried at only $8 \mathrm{~m}$ below the ground.

Hence, in this preliminary work, Comsol Multiphysics was used to simulate heat transfer between a multiple pass GHX and a cubic storage medium for heat storage and recovery purposes, with time-varying boundary conditions of the working fluid at the inlet of the pipes, in addition to the introduction of the atmospheric conditions such as regional temperature and wind speed during the simulation. The main goal of this work is to make a forecasting on heat energy quantity that can be stored and extracted from the UTES system according to several case studies, as well as estimating heat recovery efficiency.

\section{MODEL DESCRIPTION}

\subsection{Physical system}

The UTES system studied in this work as depicted in figure 1 consists of a multiple pass GHX buried in soil at a depth of $8 \mathrm{~m}$. The GHX is a duct made of copper and has an internal diameter of $10 \mathrm{~cm}$ and a thickness of $4 \mathrm{~mm}$. On the other hand, the heat storage media composed essentially of wet gravel is considered as a homogeneous and isotropic cubic porous medium having a size of $21 \mathrm{~m} \times 20 \mathrm{~m} \times 14 \mathrm{~m}$ as depicted. This storage domain is covered by a $50 \mathrm{~cm}$-sandy layer to minimize heat loss to the atmosphere.

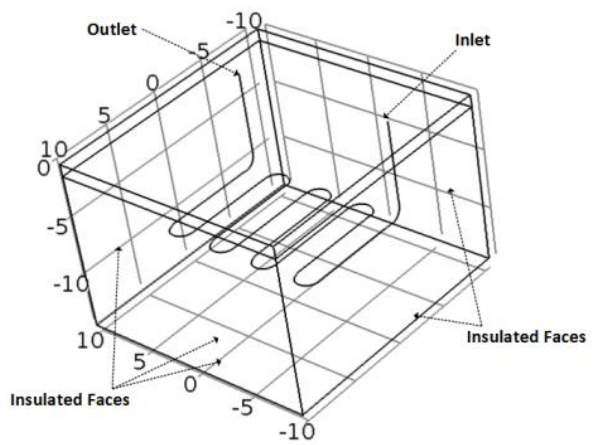

Figure 1. Geometry of the underground thermal energy system

Heat storage and recovery are realized during the charging and discharging processes by a hot fluid carrier flowing along a GHX buried at $8 \mathrm{~m}$. Performance of this heat exchanger will be evaluated according to the use of water, gasoline (organic oil) and glycol which is also used as heat carrier as well as a corrosion inhibitor. Table 1 shows physical properties of gravel while table 2 shows thermal properties for the different fluids that will be under investigation.

Table 1. Physical properties of grave

\begin{tabular}{|l|l|}
\hline Porosity & 0.15 \\
\hline Density $(\mathrm{kg} / \mathrm{m} 3)$ & 2702 \\
\hline Thermal conductivity $(\mathrm{W} / \mathrm{m} * \mathrm{~K})$ & 2 \\
\hline Specific heat $(\mathrm{J} / \mathrm{kg} * \mathrm{~K})$ & 990 \\
\hline
\end{tabular}

Table 2. Thermal properties of the investigated working fluids

\begin{tabular}{|l|l|l|l|}
\hline Fluid & Density $(\mathrm{kg} / \mathrm{m} 3)$ & $\begin{array}{l}\text { Thermal } \\
\text { conductivity } \\
(\mathrm{W} / \mathrm{m} . \mathrm{K})\end{array}$ & $\begin{array}{l}\text { Specific } \\
\text { heat } \\
(\mathrm{J} / \mathrm{kg} . \mathrm{K})\end{array}$ \\
\hline Gasoline & $650-750$ & $0.08-0.13$ & $2100-3000$ \\
\hline Water & 1000 & 0.6 & 4180 \\
\hline Glycol & $1060-1130$ & 0.252 & $2300-2700$ \\
\hline
\end{tabular}

\subsection{Finite element meshing}

The system described above was meshed using 3D tetrahedral finite elements as illustrated in figure 2, and finer grids were obtained by the aid of the meshing tool of Comsol. We did not choose to model half the geometry of the system even if the domain of interest reflects an excellent symmetry because the temperature profile along the storing domain was not expected to show any similarities above and below the GHX. However, and to gain much time, pipe flow module of Comsol was used. It is a useful tool which has the tendency to resolve heat transfer and fluid flow equations in ducts using 1D curvilinear coordinate system, thereby reducing huge time and power usually allocated for $3 \mathrm{D}$ geometries simulation.
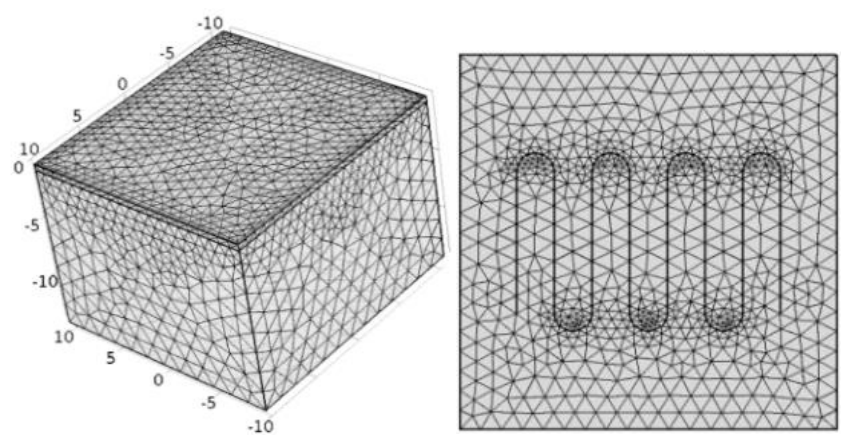

Figure 2. Meshing of the ducts and the heat storage media

The meshed domain illustrated by the sketches in figure 2 is composed of 24515 tetrahedral elements for the cubic domain and 354 edge elements for the ducts.

\subsection{Governing equations}

The governing equations describing the physics of heat storage and recovery process will be derived according to an unsteady mode. 
For the GHX, assuming a fully developed velocity profile for the working fluid and pressure drop due to viscous stress along the duct, the equations that describe heat transport and fluid flow along the duct are the following:

$$
\begin{aligned}
& \rho \frac{\partial \vec{u}}{\partial t}=-\nabla P-f_{d} \frac{\rho}{2 d_{h}} \vec{u}|\vec{u}|+\rho \vec{g} \\
& \rho A C_{p} \frac{\partial T}{\partial t}+\rho A C_{p} u \nabla T=\nabla A k \nabla T+f_{d} \frac{\rho A}{2 d_{h}}\left|u^{3}\right|-Q_{\text {wall }}
\end{aligned}
$$

- $\quad$ u: Fluid velocity inside the duct $[\mathrm{m} / \mathrm{s}]$;

- $\quad \mathrm{d}_{\mathrm{h}}$ : Hydraulic diameter $[\mathrm{m}]$;

- $\quad \mathrm{f}_{\mathrm{d}}$ : Friction factor;

- $\quad \mathrm{T}$ : Temperature profile inside the $\operatorname{duct}\left[{ }^{\circ} \mathrm{C}\right]$;

The first term on the right hand-side of equation (1) represents fluid loss due to pressure drop whereas the second term denotes losses due to viscous stresses. The third term pertains to gravity forces.

In equation (2), the second term in the right hand-side represents heat generated by viscous stresses, and the third term denotes heat dissipation through duct wall.

For the storage domain, we have considered that the system is composed of gravel - with moist air filling the void space - overlain by a sandy layer. If we consider that heat transfer inside the storage domain is solely governed by thermal conduction, and the moist air is immobile and nonreactive with the soil particles, the equation that represents transient heat transfer in a porous medium is:

$\left(\rho C_{p}\right)_{e q} \frac{\partial T_{2}}{\partial t}=\nabla k_{e q} \nabla T_{2}+Q_{\text {wall }}$

- $\quad \mathrm{T}_{2}$ : Field temperature of the porous media $\left[{ }^{\circ} \mathrm{C}\right]$;

- $\quad \mathrm{C}_{\mathrm{eq}}$ : Equivalent heat capacity of the porous medium

[J/kg.K];

- $\quad \mathrm{k}_{\text {eq }}$ : Equivalent thermal conductivity of the porous medium $[\mathrm{W} / \mathrm{m} . \mathrm{K}]$.

The equivalent heat capacity of the medium $\left(\mathrm{C}_{\mathrm{eq}}\right)$ and the equivalent heat conductivity $\left(\mathrm{k}_{\mathrm{eq}}\right)$ are evaluated according to the next formula:

$$
\begin{aligned}
& \left(\rho C_{p}\right)_{e q}=\theta_{s}\left(\rho C_{p}\right)_{s}+\left(1-\theta_{s}\right)\left(\rho C_{p}\right)_{f} \\
& k_{e q}=\theta_{s} k_{s}+\left(1-\theta_{s}\right) k_{f}
\end{aligned}
$$

Here, $\theta_{\mathrm{s}}$ represents solid volume fraction. Fluid parameters identified by the subscript " $\mathrm{f}$ " are taken as the arithmetic mean of air and moisture content.

\subsection{Initial and boundary conditions}

\subsubsection{Ducts}

The fluid carrier being initially at rest starts to flow during all the process with a mass flow rate of $0.11 \mathrm{~kg} / \mathrm{s}$. It was noticed after carrying out several simulations that this value is more suitable to achieve optimal rates for heat exchange and recovery. The temperature of the working fluid at the inlet of the duct during the charging period (May to October) is $70^{\circ} \mathrm{C}$ while during the recovery period (November to April) it is $5^{\circ} \mathrm{C}$ as shown below:

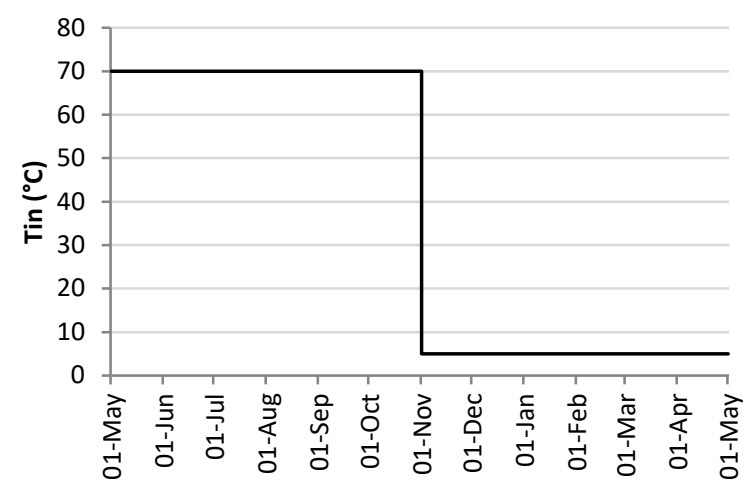

Figure 3. Temperature of the working fluid at the duct inlet

\subsubsection{Storing domain}

The initial temperature of the storage domain was set to $5^{\circ} \mathrm{C}$. The bottom and the four vertical boundaries of the storage domain were thermally isolated from the underground. Hence, Neumann boundary condition was set $\left(\mathrm{q}=0 \mathrm{~W} / \mathrm{m}^{2}\right)$. The upper surface exposed to variable atmospheric conditions was modeled by the following equation which takes into account heat transfer by convection (effect of wind speed) and radiation [5].

$\mathrm{q}_{\text {top }}=\mathrm{q}_{\text {conv }}+\mathrm{q}_{\mathrm{rad}}$

$q_{\text {top }}=\left[h_{c}\left(T_{\text {amb }}-T_{2}\right)\right]+\left[q_{\text {solar }}+\varepsilon \sigma\left(T_{a m b}^{4}-T_{2}^{4}\right)\right]$

where: $h_{c}=6.2+\left(1.4 \times u_{\text {wind }}\right)$

Here:

- $\quad \mathrm{u}_{\mathrm{wind}}$ : Wind speed near to the ground surface $[\mathrm{m} / \mathrm{s}]$;

- $\quad \varepsilon$ : Sand emissivity;

- $\quad \sigma:$ Boltzmann constant $\left[\mathrm{W} / \mathrm{m}^{2} \cdot \mathrm{K}^{4}\right]$;

- $\quad \mathrm{T}_{\mathrm{amb}}$ : Ambient temperature [C] .

Ambient temperature, wind speed and solar irradiation data had been collected from 2014 monthly weather measures proper to the city of Laghouat (Algeria), located at about $400 \mathrm{~km}$ from Algiers.

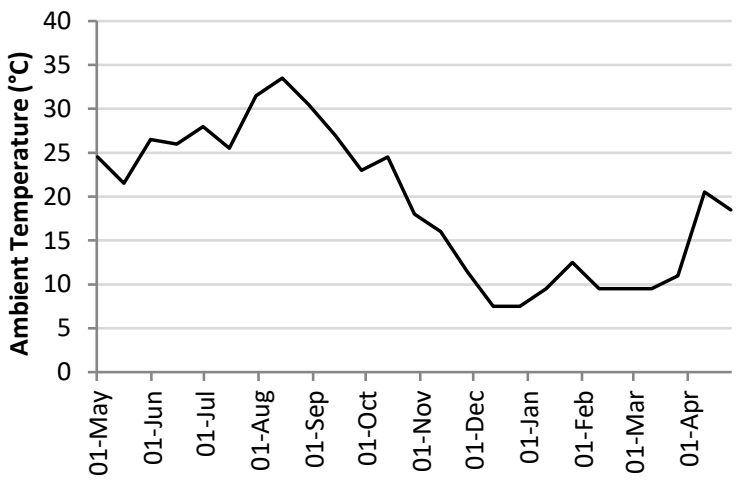

Figure 4. Temperature history in the region of Laghouat 


\subsection{Model simulation}

The unsteady simulation was carried out for a twelvemonth period, six months of heat charging (heat storage) and six months of heat discharging (heat recovery). The temperature of working fluid employed at the inlet of the pipes follows the initial and boundary conditions described above. Water as fluid carrier will be investigated at first time then the performance of other fluids will be addressed as part of a sensitivity study. The output of the simulation includes temperature of the circulating fluid and the temperature of the storing domain. Heat quantities during the charging and discharging process will be estimated by analytical formulas derived from the application of the thermodynamic equilibrium principle.

First of all, we will depict temperature distribution for a basic case in order to get a primary insight on the behavior of heat exchange between the water and the storing domain. Then, we will show the benefit of insulating the storing domain on its top for the sake of minimizing heat loss to the atmosphere especially during the recovery period.

After that, we will carry out some sensitivity cases on different fluid carrier and moisture content of the storing medium. Here, we will try to find out which fluid will be more efficient in delivering hot temperatures in cold season at high recovery efficiency.

At the end, a 10-year simulation results will be presented to show the long-term efficiency of the UTES system to yield constant performance. This will be followed by an optimization process that aims to bring up more heat energy from the storing domain.

\section{RESULTS AND DISCUSSION}

\subsection{Validation}

Validation process was carried out by comparing outlet temperature histories computed by our numerical model and Diersch's analytical solution. The results are displayed in figure 5 for the laminar and turbulent regimes with water as fluid carrier entering the duct at $90^{\circ} \mathrm{C}$ during the storing period and $10^{\circ} \mathrm{C}$ during the recovery period. These two plots show that our results are in good agreement with the Diersch's solution, and display the same trends.

These facts indicate that our UTES system reproduces well the physics of heat storage and recovery since Diersch's results were validated against experimental ones. Hence, good performance is to be expected in case of applying constant boundary conditions.

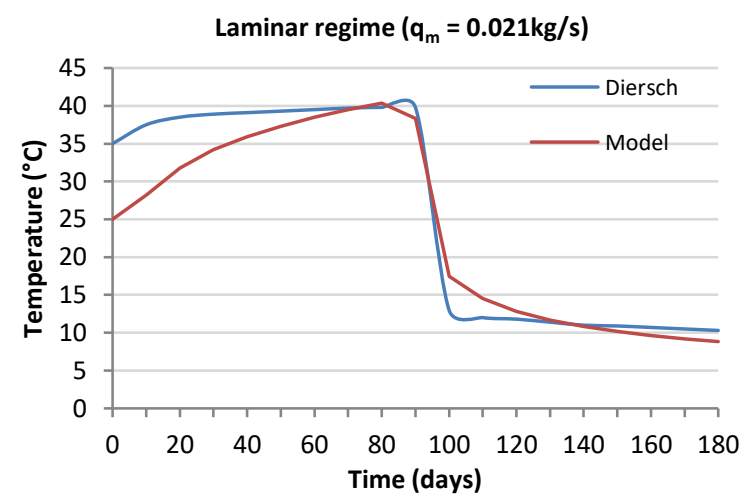

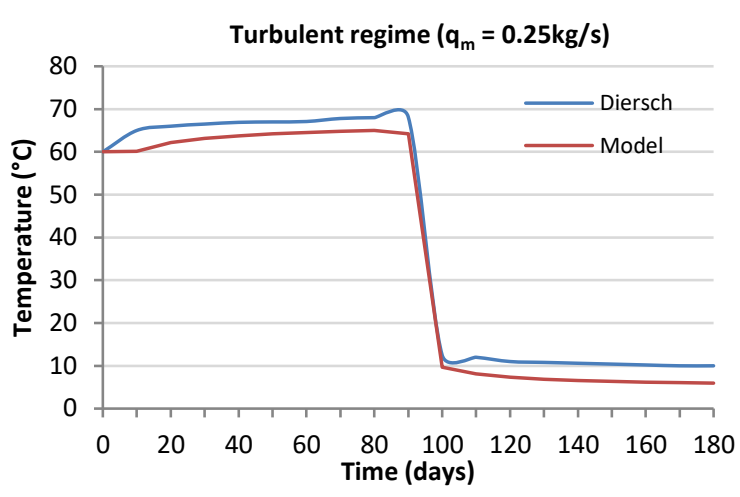

Figure 5. Results validation

Furthermore, it is noteworthy to say that the numerical model we set up is unable to show the same performance for daily-varying boundary conditions. This conclusion was also reported by Diersch \& al (2010) who stated that dailyvarying operational conditions cannot be simulated below a step-size of $10 \mathrm{~h}$ for laminar flow and about $4 \mathrm{~h}$ for turbulent flow.

\subsection{Thermal performance of storage and recovery}

Figure 6 and figure 7 illustrate several slices of the temperature profile inside the porous medium during the charging and discharging of hot water. The values next to colored scale indicate the maximum and minimum temperature inside the storage medium. Most of the heat energy yielded by the water stays concentrated around the GHX while a small amount reaches the storing domain boundaries. At the end of the charging period, the maximum temperature reaches $60^{\circ} \mathrm{C}$ around the $\mathrm{GHX}$ and approximately $30^{\circ} \mathrm{C}$ at the boundaries of the porous medium.

On the other hand, the temperature change during the first days of discharging period is extremely fast. Until the 20th day of the beginning of this process, heat transfer between water flowing across the GHX and the storing medium is performed at a high rate, where the temperature around the heat exchanger declines from $60^{\circ} \mathrm{C}$ to $25^{\circ} \mathrm{C}$. At the end of this period, heat transfer to the fluid carrier declines, and the temperature profile inside the porous medium ranges between $8^{\circ} \mathrm{C}$ and $18^{\circ} \mathrm{C}$ approximately.

In addition, it is essential to mention that from the simulation results, the stationary regime will be achieved at the day 144 of the discharging period where the temperature levels at the outlet of the GHX stay around $8^{\circ} \mathrm{C}$.

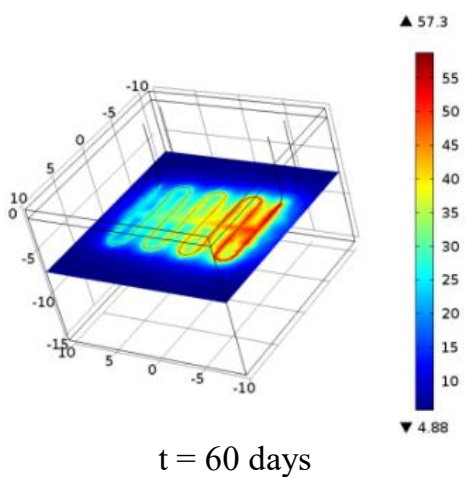




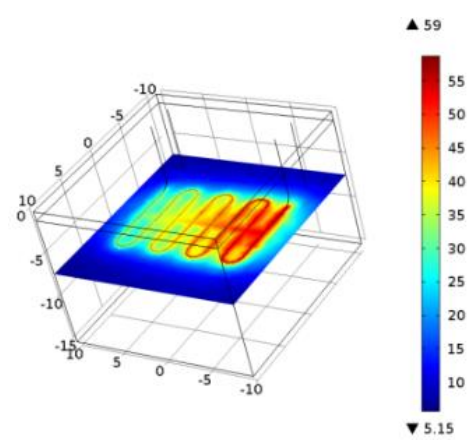

$\mathrm{t}=150$ days

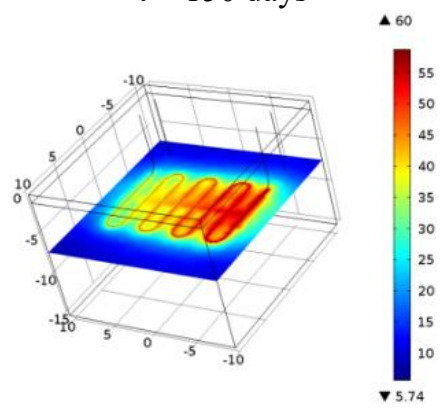

$\mathrm{t}=180$ days

Figure 6. Temperature evolution during the charging period
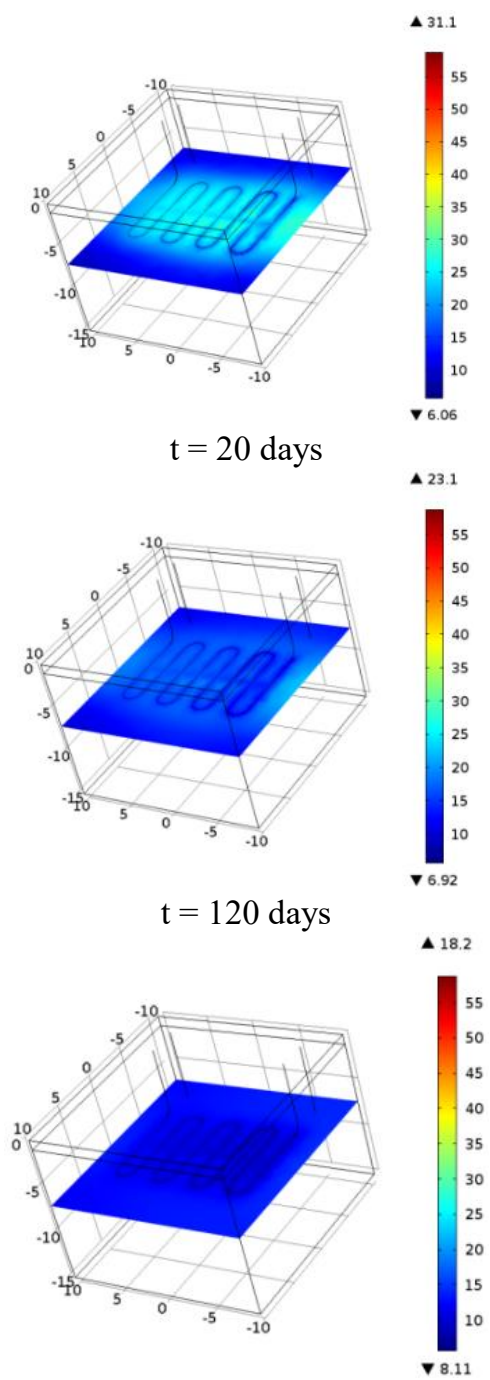

$\mathrm{t}=180$ days

Figure 7. Temperature evolution during the discharging period
For both the two phases, heat exchange between the fluid carrier and the porous medium was stronger during the first days than the last days. This decline of heat exchange is primarily due the weak thermal diffusivity of the underground material, i.e. gravel, that impeached an efficient diffusion of heat to and from the porous medium. That's why a considerable amount of heat is still kept inside the domain as its temperature at the end of the recovery stage ranges between 8 and $18^{\circ} \mathrm{C}$, while the temperature level delivered at the outlet of GHX, see figure 8 , evolve from $25^{\circ} \mathrm{C}$ down to $5^{\circ} \mathrm{C}$.

Consequently, as soon as the storage domain gets warmer, less heat quantity is delivered from the hot fluid carrier to the porous domain, and that's why the fluid temperature at the outlet of the GHX tends to increase with time. On the other hand, the outlet temperature of the fluid during the heat extraction period tends to decrease with time, which means that less heat is delivered to the fluid carrier as the porous domain is getting colder around the GHX, and this zone seem to act as barrier to transfer more thermal energy.

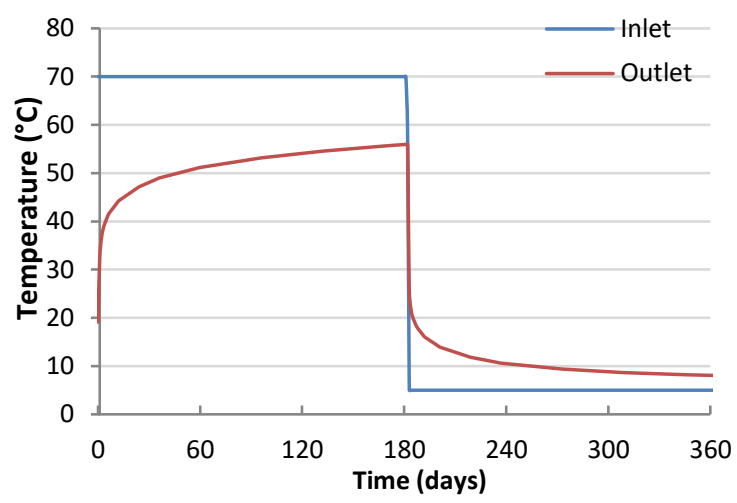

Figure 8. Fluid carrier temperature at the inlet and outlet of the GHX

Figure 9 shows a general view of the storing domain at the end of the charging process where a total of 40 planes have been sketched. It easily seen that the temperature distribution around the GHX follows a parabolic trend and the temperature difference near the vertical boundaries of the storing domain is extremely small due to thermal insulation applied on those boundaries.

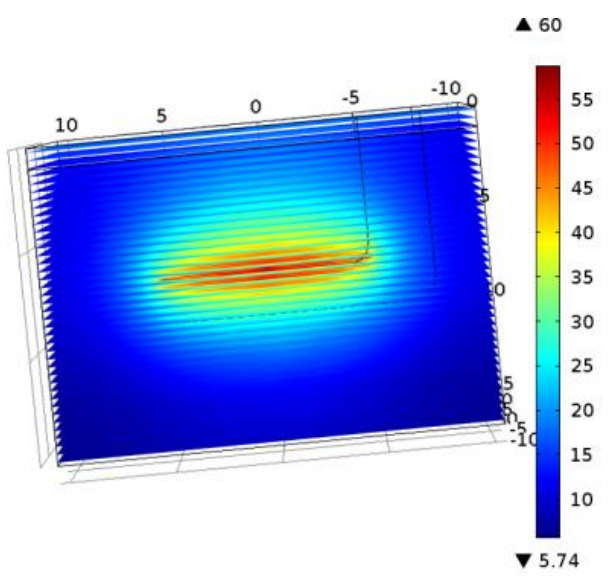

Figure 9. Temperature distribution around the GHX 


\subsection{Effect of thermal insulation on the top layer}

By adding a sandy layer as a means to reduce heat loss to the atmosphere, we noticed a significant decrease in the outward heat flux. This fact is shown by figure 10 where we can see that heat loss during cold season (last six months of the period of interest) is tremendously reduced after insulating the top of storing domain.

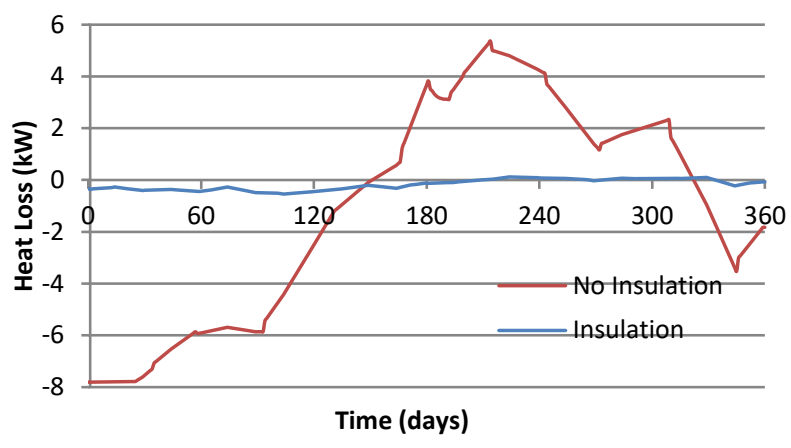

Figure 10. Heat loss to the atmosphere

\subsection{Moisture content sensitivities}

In this part of work, a parametric study was run according to different moisture content " $\omega$ " $(10 \%, 33 \%$ and $47 \%)$ that characterizes partially saturated media. From figure 11, the temperature of water at the outlet of GHX followed the same trend whatever the moisture content was, and this fact was the same when using glycol or gasoline.

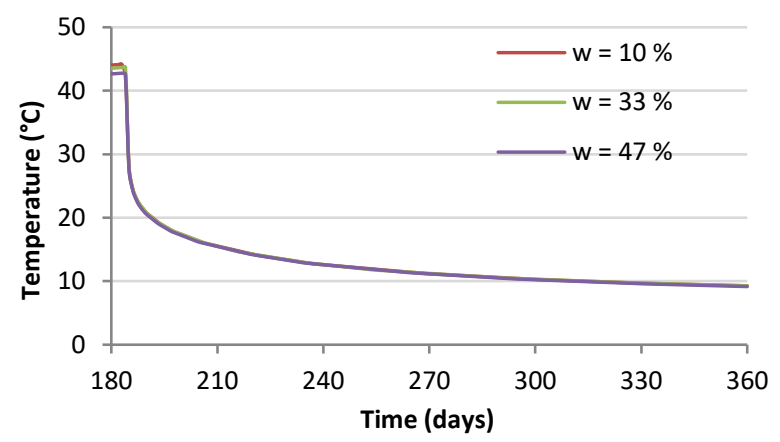

Figure 11. Temperature of the fluid carrier at the outlet of the GHX

After 30 days of the discharging process, the temperature of water $15^{\circ} \mathrm{C}$ at the outlet of the GHX, while at the end, it stabilizes at about $10^{\circ} \mathrm{C}$. So, we can conclude that moisture content of the storing medium does not affect tremendously the yielded temperature during heat recovery.

\subsection{Fluid carrier sensitivities}

In this sensitivity study, we wanted to find out which fluid carrier will deliver high temperature especially during cold season where heat demand is high. We ran three simulation cases according to the three working fluids described table 2 .

The results plotted in figure 12 show that gasoline is more likely to deliver high temperatures than water and ethylene glycol. After 30 days of the discharging process temperatures on the outlet of duct is respectively $26^{\circ} \mathrm{C}, 16^{\circ} \mathrm{C}$ and $14^{\circ} \mathrm{C}$ for gasoline, water and glycol. This trend continues to decline with time. At the end of this stage, the temperature at the outlet of duct reaches $12^{\circ} \mathrm{C}$ in case of using gasoline, whereas when we use glycol or water, the temperature will be approximately $8^{\circ} \mathrm{C}$.

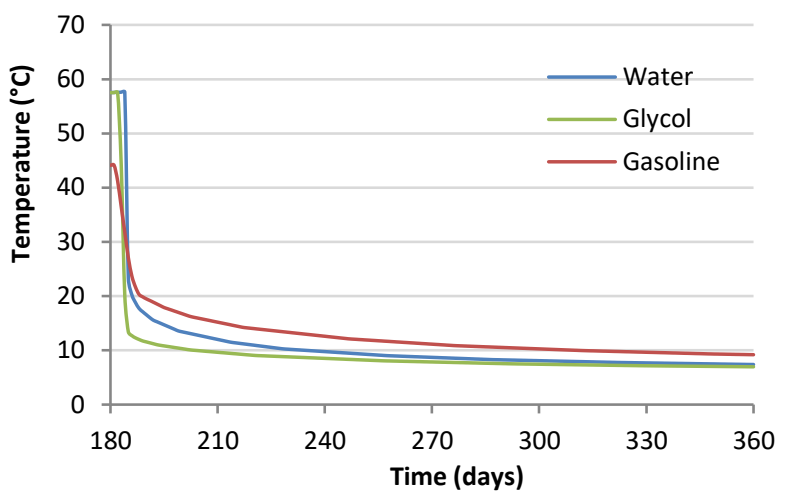

Figure 12. Temperature of the fluid carrier at the outlet of the GHX

\subsubsection{Heat recovery efficiency}

The amount of heat stored is simply determined from the difference between the temperature of working fluid at the inlet and at the outlet of the pipes during the charging period. The same approach is applied to estimate the amount of heat recovered during the discharging period. Formulas (7) and (8) will be used to perform the calculations.

For the charging period:

$\mathrm{Q}_{\text {stored }}=\left.\dot{\mathrm{mC}_{\mathrm{p}}}\left(\mathrm{T}_{\text {in }}-\mathrm{T}_{\text {out }}\right)\right|_{\text {storage }}$

For discharging process, the amount of heat recovered is the sum of heat yielded by the 2 ducts:

$Q_{\text {recovered }}=\left.\sum \dot{m} C_{p}\left(T_{\text {in }}-T_{\text {out }}\right)\right|_{\text {Recovery }}$

Hence, recovery efficiency " $\eta$ " will be calculated by formulae (9):

$\eta=\frac{Q_{\text {recovered }}}{Q_{\text {stored }}}$

The results indicating the cumulative heat quantities during the charging and the discharging processes are shown in figure 13 .

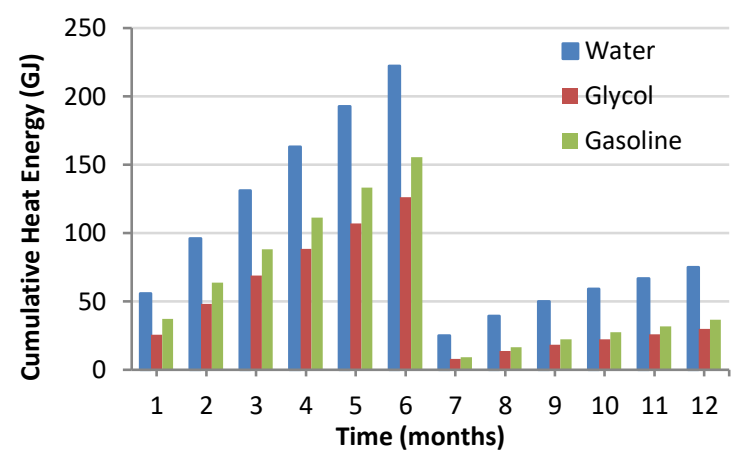

Figure 13. Cumulative heat stored and recovered for the fluid carrier sensitivities 
The important fact given by figure 13 is that water as a fluid carrier is a good solution for operating our UTES system, as it allows for the storage and recovery of great amount of heat energy than gasoline or glycol. Moreover, recovery efficiency yielded by using water is of great interest (see figure 14). So, the choice of water as a fluid carrier is clearly justified for application and design of any UTES system, but some enhancement has to be done in order to extract more heat from underground and make the system more viable, and this will be developed later in this paper.

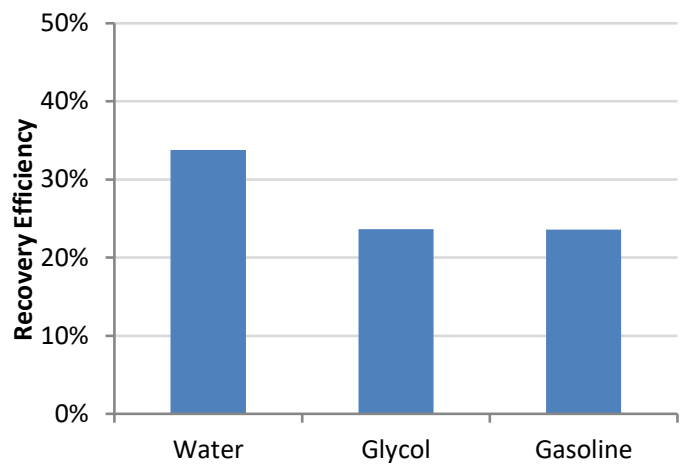

Figure 14. Heat recovery efficiency

\subsection{Long-term performance}

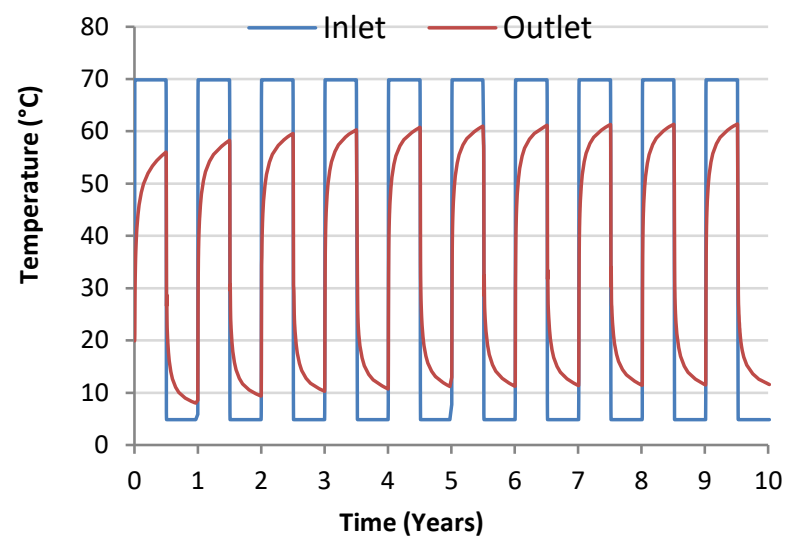

Figure 15. Outlet temperature of the fluid carrier for a 10 year period

Long-term performance is a key parameter to determine stable and efficient operational conditions of the UTES system studied herein and to justify eventual investments as part of setting up of such systems for pilot or large-scale projects.

To investigate this point, a ten-year period simulation was carried out by changing the temperature input of the fluid carrier every six months to make an alternating operation between storage and recovery.

The results obtained by doing this task are depicted in figure 15 . This plot indicates that outlet temperature history of water across the years is nearly constant.

\subsection{Heat recovery optimization}

In order to enhance heat recovery of the system, we have chosen to incorporate 2 ducts having the same geometry and properties within the storing domain (figure 15). These ducts will be exclusively used during cold period for the sake of gathering more heat from underground. The fluid carrier flows through those 2 ducts with a flowrate of $0.11 \mathrm{~kg} / \mathrm{s}$ and temperature of $5^{\circ} \mathrm{C}$.

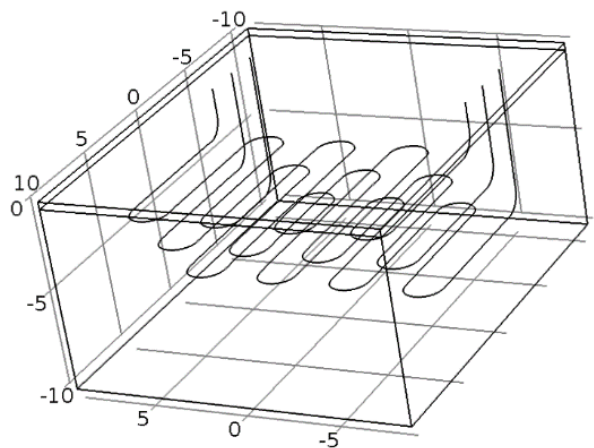

Figure 16. System geometry for heat recovery optimization

Figure 16 shows the recovered temperature obtained after carrying out the simulation. The temperature of the fluid carrier at the outlet of the upper duct evolves from $35^{\circ} \mathrm{C}$ to $14^{\circ} \mathrm{C}$ while at the inlet of the lower duct, the temperatures evolves from $36^{\circ} \mathrm{C}$ to $15^{\circ} \mathrm{C}$. This fact indicates that the 2 ducts delivered more temperature levels more than the primary duct did alone and allowed for a more heat to be extracted. The net increase is illustrated in figure 17 .

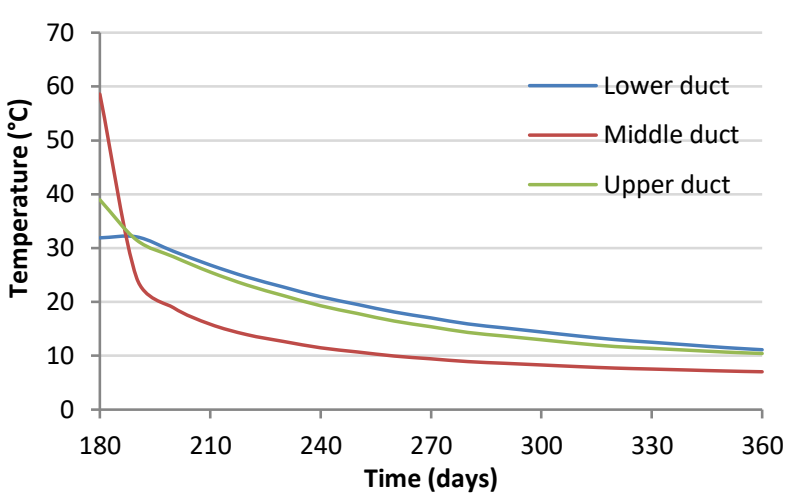

Figure 17. Outlet temperature for the different ducts

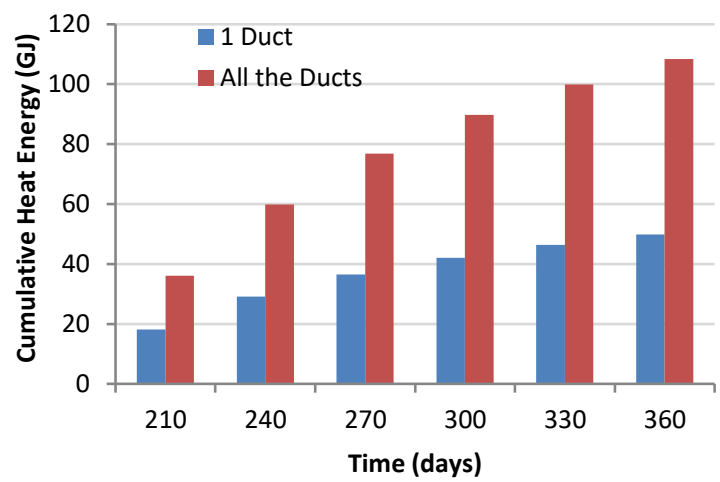

Figure 18. Cumulative heat delivered by the 3 ducts

At the end of the recovery period, the ducts altogether brought up nearly 108 GJ of cumulative heat energy, which represents a net increase of about 58.5 GJ in comparison with the initial system performance. As a result, the recovery efficiency will go up from $33.8 \%$ to $68.6 \%$. 
This increase in heat extraction has led to a decrease in the mean temperature of the porous medium as reported by figure 18. The average temperature of the porous domain at the end of the recovery stage, after carrying out optimization tasks, went down to $13^{\circ} \mathrm{C}$, which represents a net decrease of about $5^{\circ} \mathrm{C}$ in comparison of the $18^{\circ} \mathrm{C}$ obtained when only one duct was used to perform heat recovery process.

The points described in this section are good indicators of the improvements made on recovery process, but they also tell us that there is still to do to get back heat amounts trapped in the storing domain.

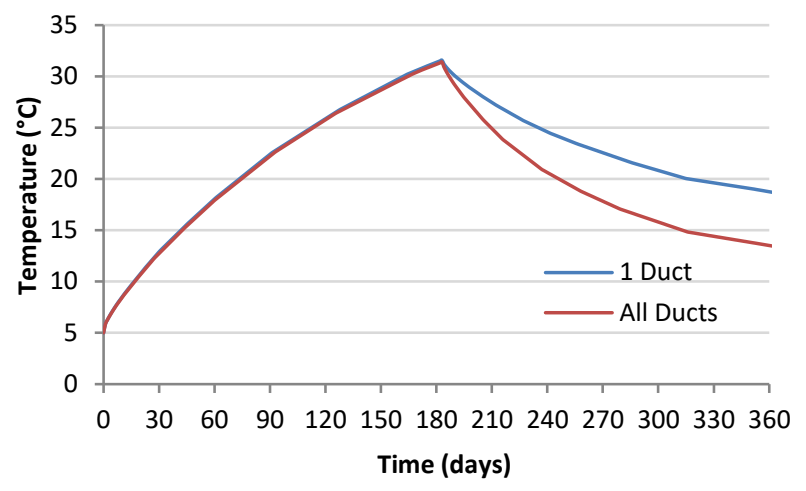

Figure 19. Average temperature of the porous domain

\section{CONCLUSION}

The aim of this work was to assess the performance of an innovative UTES system destined for heat storage and recovery. Several forecasting tasks were made along this paper in order to evaluate heat recovery and recovery efficiency of the system during a twelve-month period, i.e. six month of hot season for heat storage and six cold months for recovery.

Fluid sensitivity simulation has shown that water as a fluid carrier is very advantageous during the whole process of UTES. It allows for large heat amount to be stored and extracted more than gasoline and glycol can do, in addition to the excellent recovery efficiency and the acceptable temperature levels delivered at the outlet of GHX. The simulation results on the effect of moisture content appear to have no influence on the performance of the recovery phase. Long-term assessment, after carrying out a ten-year simulation, has demonstrated that the performance of our UTES system will keep showing stable and improved performance year after year.
All the results of this study have determined that investigating horizontal distances for heat storage purpose can be very beneficial in terms of technical and economic feasibility, having in mind the costs and technical barriers to drill deeper boreholes into the ground. It has also given us a good insight on the capabilities of this novel UTES system to show the same performance as other classical systems do.

This work will be improved in the future where we will explore other solutions to recover the amount of heat still remaining underground Furthermore, we will try to optimize the design of the UTES system studied herein and couple it with buildings or a set of houses in order to satisfy their seasonal heat energy needs.

\section{REFERENCES}

[1] A. Medjelled, A. Benchatti, A. Bounif, "Experimental model for the study of heat transfer in unsaturated soil: Case of underground thermal storage," International Journal of Heat and Technology, vol. 26, no. 1, pp. 95-102, 2008.

[2] D. Chiasson, "Modeling horizontal ground heat exchangers in geothermal heat pump systems," in Proc. Comsol conference, Boston, 2010.

[3] S. Lanini, F. Delaleux, X Py, R Olivès, D. Ngyuen, "Improvement of borehole thermal energy storage design based on experimental and modelling results energy and buildings," in Proc. Energy and Buildings, 2014.

[4] J. G. Diersch, D. Bauer, W. Heidemann, W. Ruhaak, P. Schatzl, "Finite element modeling of borehole heat exchanger systems - Part 1. Fundamentals," Journal of Computer and Geosciences, vol. 37, pp. 1122-1135, 2011. DOI: $10.1016 /$ j.cageo.2010.08.003.

[5] J. G. Diersch, D. Bauer, W. Heidemann, W. Ruhaak, P. Schatzl, "Finite element modeling of borehole heat exchanger systems - Part 2. Numerical simulation," Journal of Computer and Geosciences, vol. 37, pp. 1136-1147, 2011. DOI: 10.1016/j.cageo.2010.08.002.

[6] Y. Rabin, E. Korin, E. Sher E., "A simplified model for helical heat exchanger for long-term energy storage in soil, "in Proc. EUROTHERM Seminar $N^{\circ}$ 18, Hamburg, Germany, Feb. 27-Mar. 5, 1991, pp. 305-314.

[7] B. Welsch, W. Ruhaak, D. O. Schulte, K. Bar, S. Homuth, I. Sass. (2015). Technical and economical evaluation of medium deep borehole thermal energy storages. [Online]. 